\title{
Power Saving Management in Ad-Hoc Wireless Network
}

\author{
M. M. EL-GAZZAR ${ }^{1} \&$ BEN BELLA S. TAWFIK ${ }^{2}$ \\ ${ }^{1}$ College of Computers \& Informatics, Cairo, Egypt \\ ${ }^{2}$ College of Computers \& Informatics, Suez Canal University, Ismailia, Egypt
}

\begin{abstract}
:
In wireless network Power Saving is an important issue. In this work power savingis done via a sequence of procedures. Power Saving (PS) function describes the necessary steps for a station in PS mode to turnoff the transmitter and receiver circuitry, to inform other stations or to retrieve information about pending packets, and to transmit or receive traffic. The PS function is different for ad hoc and infrastructure networks. The PS function for an IBSS (ad hoc network) operates in a distributed manner.A station that wants to enter the PS mode has to successfully complete a frame exchange with another station with the power bit set in the frame header. Note that neither a specific station nor all stations need to be informed. The power-saving status estimation is based upon local information or the last data frame exchange with that station. The IEEE standard leaves open the solution to the problems of how the estimate is created and on which information the estimate is based.
\end{abstract}

Key words: Power Saving PS -Ad Hoc - IEEE standard - IBSS

\section{Council for Innovative Research}

Peer Review Research Publishing System

Journal: INTERNATIONAL JOURNAL OF COMPUTERS \& TECHNOLOGY

Vol 6, No 1

editor@cirworld.com

www.cirworld.com, member.cirworld.com 


\section{1- Introduction:}

The Power Saving (PS) function describes the necessary steps for a station in PS mode to turn off the transmitter and receiver circuitry, to inform other stations or to retrieve information about pending packets, and to transmit or receive traffic [1]. The PS functionis different for ad hoc and infrastructure networks. The PS function for anIBSS (ad hoc network) operates in a distributed manner. That is, frames destinedto nodes in PS mode have to be buffered locally instead of at a centralized facility.A station that wants to enter the PS mode has to successfully complete a frameexchange with another station with the power bit set in the frame header. Notethat neither a specific station nor all stations need to be informed [4]. Once the frameexchange has been successfully completed, the station may enter the PS state. In thePS state, the station has to wake up periodically at the estimated time of a beacontransmission. The station is further required to stay "awake" for a period referred toas the ATIM window to receive announcements from other stations with bufferedtraffic. The ATIM window can be used by the station itself to announce bufferedtraffic. If there is no traffic announcement for the station, the PS state is reentered.If an announcement in the form of an ATIM arrives, the station has to acknowledgethe ATIM and has to stay "awake" beyond the ATIM window until all ofthe announced buffered frames were received. During the data frame transmissionperiod that follows the ATIM window, announced traffic can be sent followingthe basic channel access rules. Both form the beacon interval. The PS specificationrequires a station desiring to transmit a frame to another station to estimate thepower-saving status of the other station. The estimate can be based on local informationor the last data frame exchange with that station. The IEEE standard leavesopen the solution to the problems of how the estimate is created and on whichinformation the estimate is based [3]. Figure 1 shows two stations operating in PS (power saving) mode. Both stations are requiredto wake up upon every beacon and to listen throughout the ATIM window. Station2 wishes to send a frame to station 1 and therefore announces that frame by an ATIM. Station 1 responds with an ACK, whereupon station 2 starts data frametransmission after completion of the ATIM window, the PS state, the sendingstationcreates an ATIM, which is sent during the ATIM window. Once the ACKof the intended station is received, the station sends the data frame after completionof the ATIM window. It is assumed that a station always is in PS mode if it has notexplicitly indicated that it will stay awake by an ACK in response to an ATIM (evenin the case that it is awake because it has pending traffic) $[5,6]$.

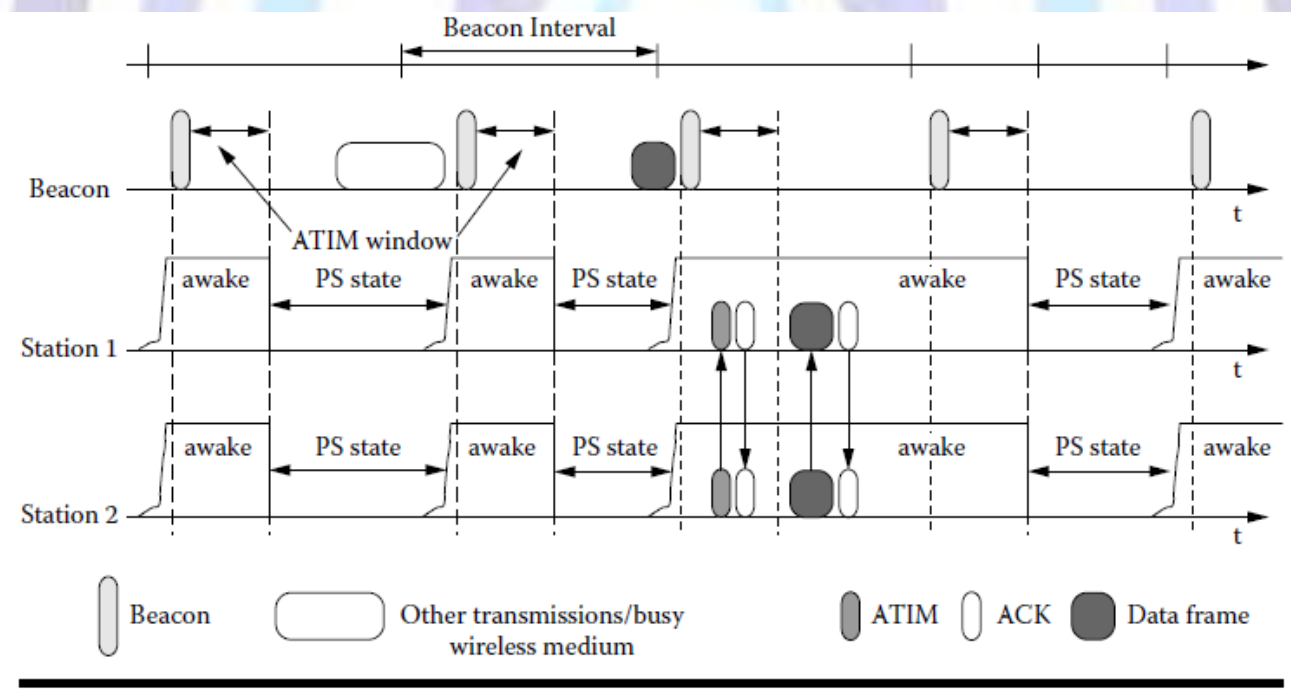

Figure 1: Two stations Operating in Power Saving mode

\section{2- Proposed Model}

The model reflects for each period of time, the sending time (uniform random selection) for each station, and the receiving time (uniform random selection) for each station.The model has the following assumptions, 1 . Analysis is done for 100 periods of time, each is $10 \mathrm{mS}$ (total time $=10^{*} 100=1 \mathrm{sec}$ ), and 2. Number of stations (in this program) $n=50$ (can be changed), scattered randomly, where each one has the same weight.

\subsection{Discussing the sleeping time in each period of time (1-100)}

It means that analyzing the power saving which is function of the sleeping time.

Whatever the procedure, the end result during the sleeping time in each period of time for each station is either acquired or not (not acquired in case of sending or receiving).

Assume for each station, during each period of time $\mathrm{T}=10 \mathrm{~ms}$, is divided into three regions

$\mathrm{t} 1=1 \mathrm{~ms}$ (beacon time)

$\mathrm{t} 2=4 \mathrm{~ms}$ (awaketime)

$\mathrm{t} 3=5 \mathrm{~ms}$ (sleepingtime) 


\subsection{Algorithm}

Inputs: Assuming the slot time $=100 \mathrm{~ms}$, Number of time periods $=100$ period, and Number of stations $=50$

For each time slot, np, from 1 to 100 , check if in this time slot there is a backoff (or) reservation for sending from previous sending.

If there is a previous reserving, give it the high priority.

Formulate a vector of length equal to number if stations, with values zeros and ones (ones mean this station require a sending, zero means no sending. The probability of sending for each station is 0.01 .

Add the previous sending station in first.

Check the number of sending at this time slot, there are three cases.

Number of sending is zero, power saving, go to the next time slot.

Number of sending is equal to 1 , no collision. Pick randomly the receiving station, save the sending and receiving station number for this time slot and change the sleeping time to be zero for both sending and receiving (add it to the awake time).

In case of number of sending is bigger than 1(collision), reschedule the second, the third ..........and so on station for the next time slots with random selection to avoid collision. Keep the first station to be sending this time slot and do the same sequence as number of sending is equal to one.

For each station do the calculation by summing the cumulative awake /sleep time at each time slot

For the whole network calculate the network cumulative awake/sleep time.

Plot different graphs, open a text file and save the collision parameters.

Figure 2 shows the proposed model flow chart. Note that the network awake time in a specific period of time t2 for the network = maximum of $\mathrm{t} 2$ for all the stations at this period of time.The network sleep time in a specific period of time $\mathrm{t} 3$ for the network $=$ minimum of $\mathrm{t} 3$ for all the stations at this period of time.

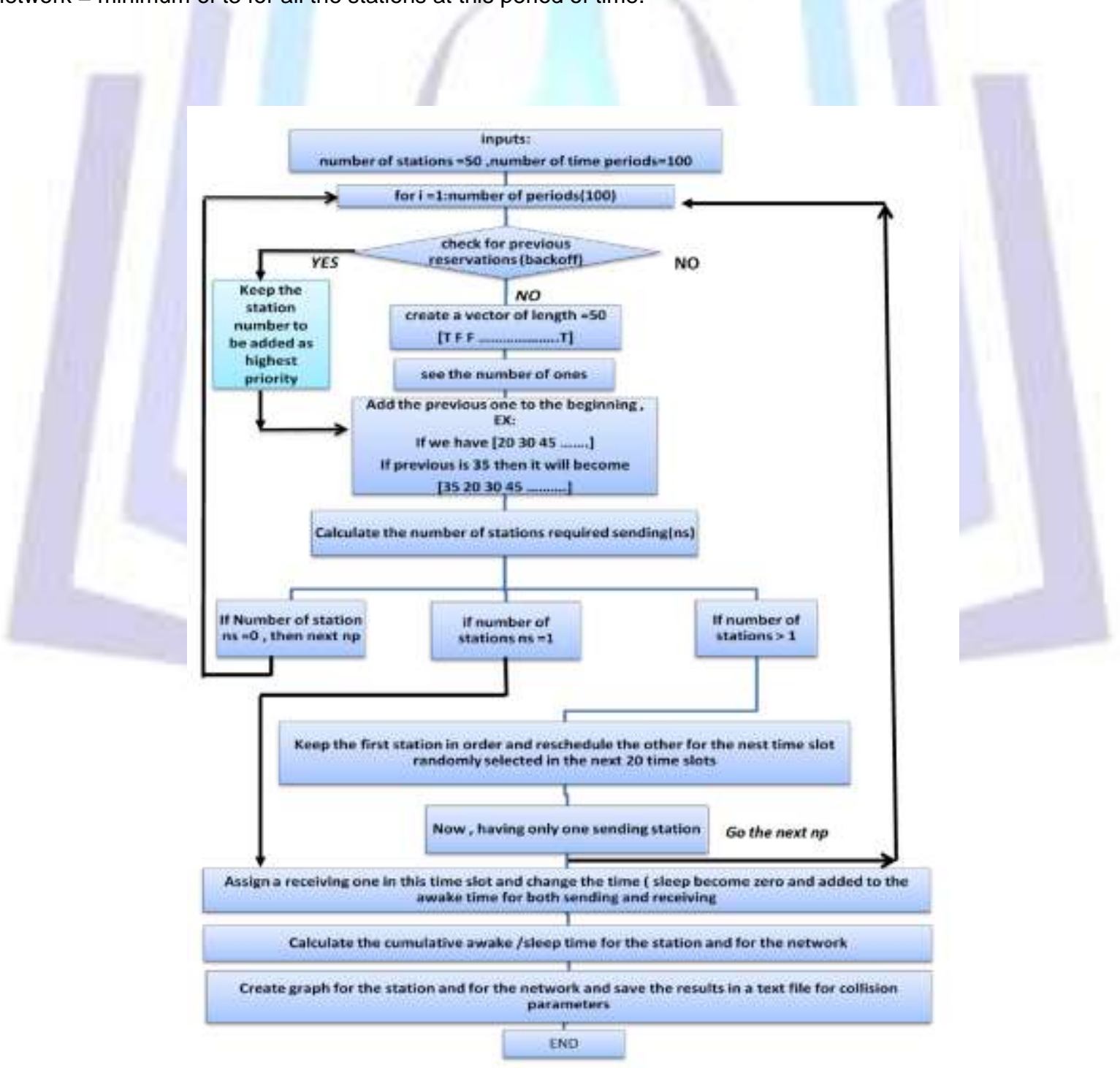

Figure 2: Flowchart of the proposed model 


\section{Results}

For each station:

Calculate the commutative awake time, in other words, at a period =np, the awake commutative time = $(\mathrm{t} 1+\mathrm{t} 2) 1+(\mathrm{t} 1+\mathrm{t} 2) 2+(\mathrm{t} 1+\mathrm{t} 2) 3+$ .$(\mathrm{t} 1+\mathrm{t} 2) \mathrm{np}$.

Calculating the commutative time (logic) so at period $\mathrm{np}=20$. For example the commutative time $=T^{*} n p=$ $10 \mathrm{~ms}^{\star} 20=200 \mathrm{msec}$.

Calculate the relative awake time (utilization time) which is equal to the awake time divided by the commulative time at a specific period np.

Then repeat for the sleeping time.

Now plot the commutative time with the awake -relative time, for each station. Note that the result is random because each station has the same weight. (No base station, no location effect).

Table 1 illustrates the result of the simulation.

Figure 3 describes the network utilization time analysis, it shows that the stability is maintained after almost 300 milisecond which is the normalized network awake time with the total time. The steady state value is about 0.77 .

\section{Conclusion}

In this work, the effect of changing number of stations is introduced. In theillustrated figures, plot the sum of awake time for each station till the end of the last period of time, then dividing this sum by the total time and taking the average of this relative time by dividing it by the number of stations. In other words:

Relative- average-awake time $=\frac{\sum_{n=1}^{n u m b e r} \text { ofstaions } \text { awake -timeforstationn /(totaltime ) }}{\text { numberofstations }}$

Note that for each station, the sum of awake time/relative time and sleeping time/relative time is always equal to 1 at each time.It can be concluded that the simulation results emphasize matches the logic reality. Also, the model describes different collision cases and reschedules the transmission without affecting the network performance.

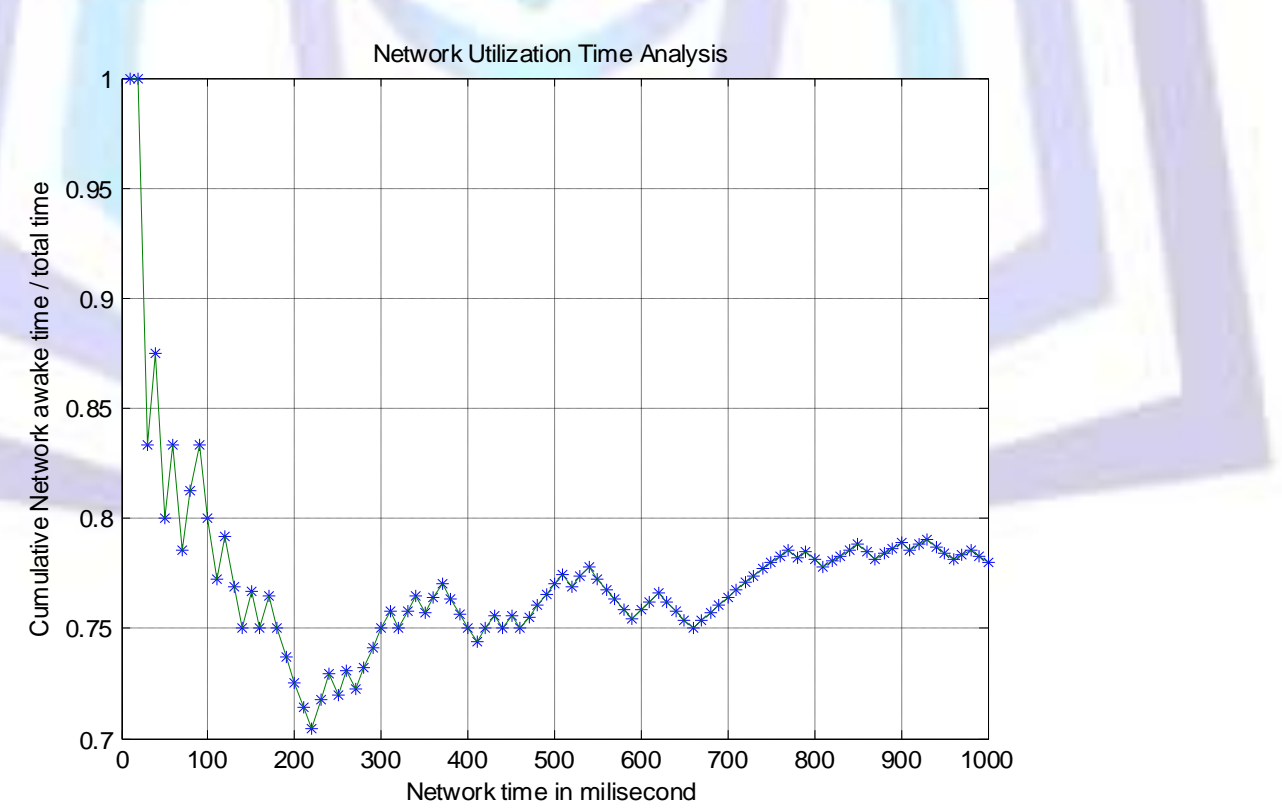

Figure 3: Network utilization time 


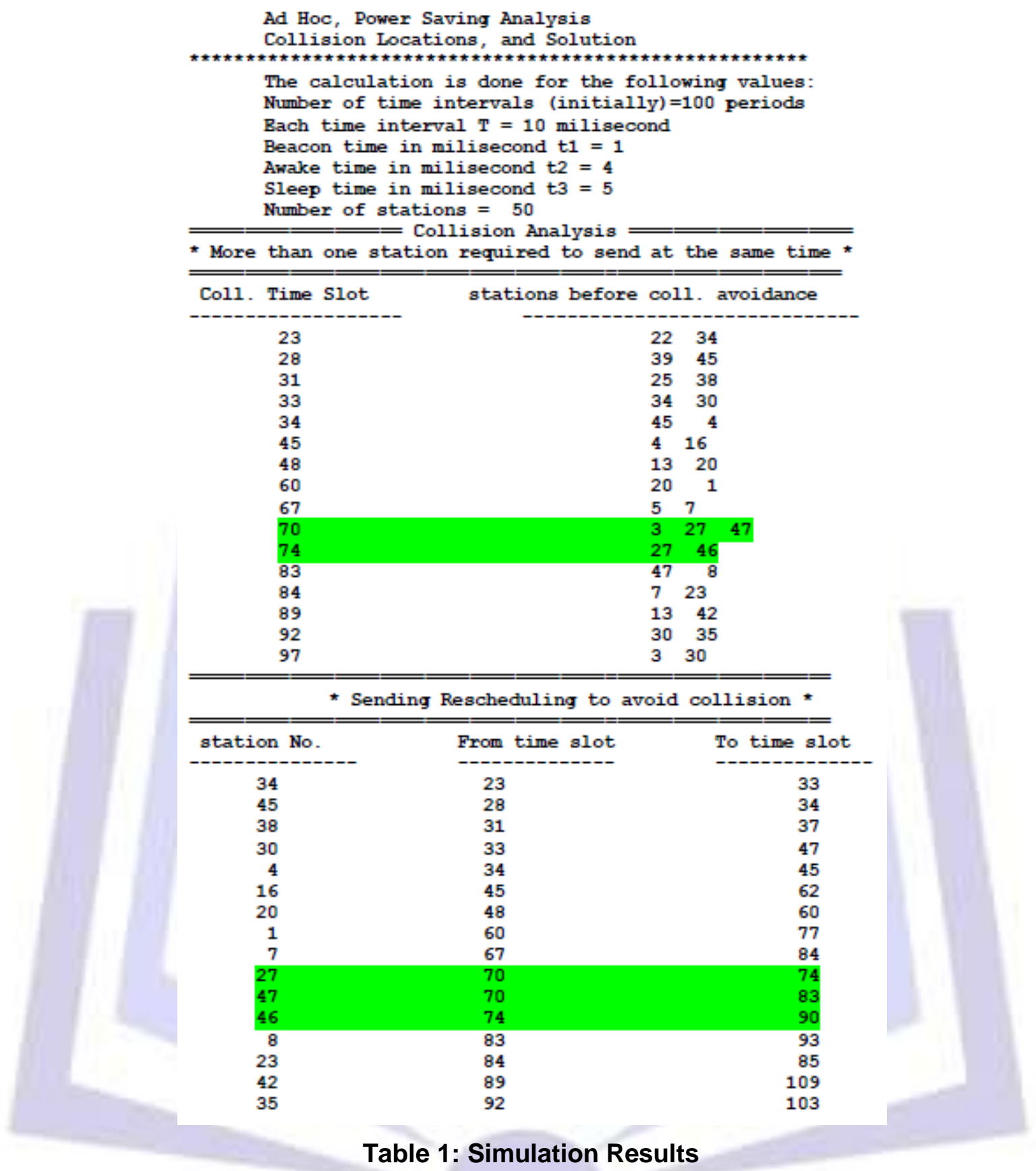

\section{References:}

Alemdar, A.; Ibnkahla, M. Wireless Sensor Networks: Applications and Challenges. In Proceedings of the 9th International Symposium on Signal Processing and Its Applications, Sharjah, United Arab Emirates, 2007; pp. 1-7.

H. Balakrishnan, S. Seshan, E. Amir, and R. H. Katz. Improving TCP/IP Performance OverWirelessNetworks. In Proceedings of the First Annual ACM/IEEE International Conference on Mobile Computing and Networking (MobiCom'95), pages 2-11, November 1995.

ImadAad and Claude Castelluccia. Differentiation Mechanisms for IEEE 802.11. In Proceedings ofIEEE INFOCOM 2001, pages 209-218, Anchorage, Alaska, April 2001.

Jin, Z.; Ping, Y.; Wang, Z.; Ping, L.; Guang, L. A survey on position-based routing algorithms in wireless sensor networks. Algorithms 2009, 2, 158-182.

Kandris, D.; Tsioumas, P.; Tzes, A.; Nikolakopoulos, G.; Vergados, D. Power conservation through energy efficient routing in wireless sensor networks. Sensors 2009, 9, 7320-7342.

Liao, W.; Chang, K.; Kedia, S. An Object Tracking Scheme for Wireless Sensor Networks using Data Mining Mechanism. In Proceedings of the Network Operations and Management Symposium, Maui, HI, USA, 2012; pp. 526-529. 
Michael Barry, Andrew T. Campbell, and AndrasVeres. Distributed Control Algorithms for ServiceDifferentiation in Wireless Packet Networks. In Proceedings of IEEE INFOCOM 2001, pages 582-590, Anchorage, Alaska, April 2001.

Nikoletseas, S.; Spirakis, P.G. Probabilistic Distributed Algorithms for Energy Efficient Routingand Tracking in Wireless Sensor Networks. Algorithms 2009, 2, 121-157.

Tubaishat, M.; Zhuang, P.; Qi, Q.; Shang, Y. Wireless sensor networks in intelligent transportation systems. Wirel.Commun.Mob.Comput. 2009, 9, 287-315.

Vidhyapriya, R.; Vanathi, P. Energy Aware Routing for Wireless Sensor Networks. In Proceedings of the International Conference on Signal Processing, Communications and Networking, Chennai, India, 2007; pp. 545-550.

VaduvurBharghavan, Alan Demers, Scott Shenker, and Lixia Zhang. MACAW: A Media AccessProtocol forWireless LAN's. In Proceedings of the SIGCOMM '94 Conference on CommunicationsArchitectures, Protocols and Applications, pages 212-225, August 1994.

Wood, A.; Stankovic, J.; Virone, G.; Selavo, L.; Zhimin, H.; Qiuhua, C.; Thao, D.; Yafeng, W.;Lei, F.; Stoleru, R. ContextAware wireless sensor networks for assisted living and residentialmonitoring. Network 2008, 22, $26-33$. 